\title{
Sustainable e-Governance and Human Resource Development
}

\author{
Sorin Burlacu ${ }^{1}$, Cristina Alpopi ${ }^{1}$, Marcela Mitrită ${ }^{1}$ and Maria-Loredana Popescu ${ }^{1}$
}

\begin{abstract}
Much of the literature focusing on organizational change suggests that changes often fail because of employees' resistance. This resistance is caused by their personal fears that change will affect them in any way. Employees are often afraid of changes that could lead to changes in comfortable social dynamics and to additional, less desirable or even more difficult tasks. The proliferation of new technologies brings new challenges but also concerns about job stability. Our paper addresses the issue of human resources development from e-government perspective and presents some features that could be considered when promoting technologies especially in sensitive areas such as public administration. The methodology of research aimed at measuring and interpreting a set of economic, technical and social aspects present in public organizations in Romania. The research findings show how HR is transforming into the digital era and what one might consider to bridge the gap between knowing and doing what is needed to put technology together with the latest processes and skills for a sustainable development of human resources.
\end{abstract}

Keyword: e-HR, the digital era, the development of human resources

\section{Introducțion}

The term e-governance or electronic governance has been published relatively recently since 2001 in the databases of the scientific publications of Web of Science. Fifteen years later, however, this topic is the culmination of the debate, not less than 110 papers (fig. no. 1), giving it a central place in the research area. Recontextualization of the concept has not been expected, so in 2017 over 650 works mentioned in their references refer to works that approached this concept (fig. no. 2). In the field of human resources, research published in the Web of Science from 1975 to present amounts to more than 100,000. Most, over 14,000 are in the field of Management followed by Environmental Science (fig. No 3.).

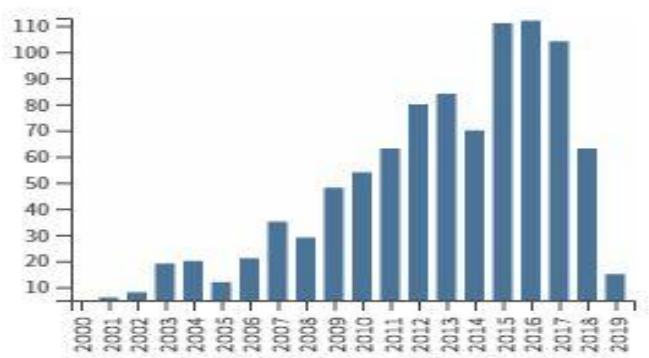

Fig. No.1: Total Publications by Year

Source: Web of Science 


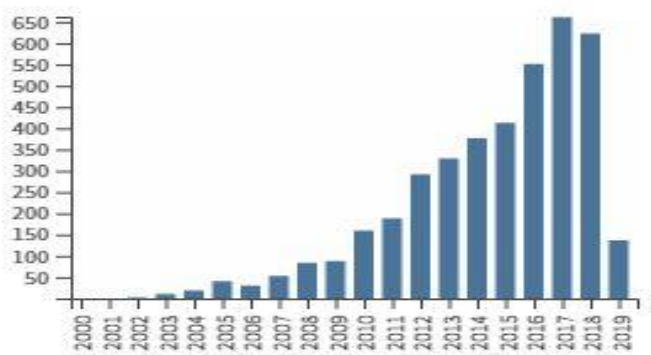

Fig. No.2: Sum of Times Cited by Year

Source: Web of Science

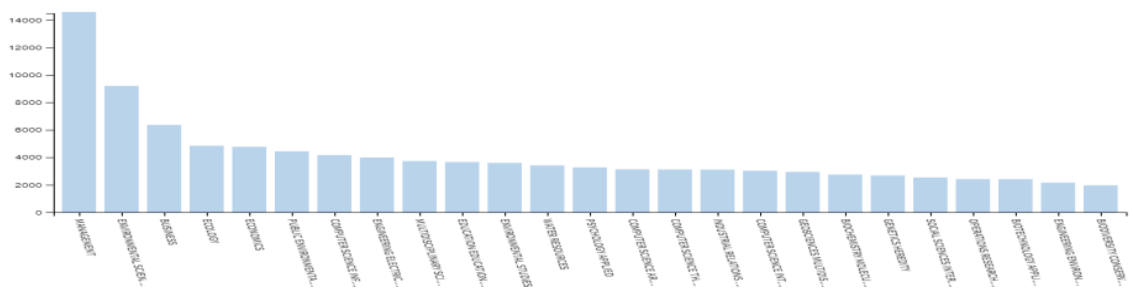

Fig. No.3: Human Resorces in Web of Science Categories

Source: Processing results from http:/ / wcs.webofknowledge.com/ $\mathrm{R} A$ / analyze.do

The concept of sustainability is debated in over 133,000 scientific papers published in the Web of Science. Of these, more than 25,000 are in the field of environmental sciences followed by environmental studies and technologies. A suggestive image is found in fig. no. 4 and represents the analysis of Clarivate Analytics results.

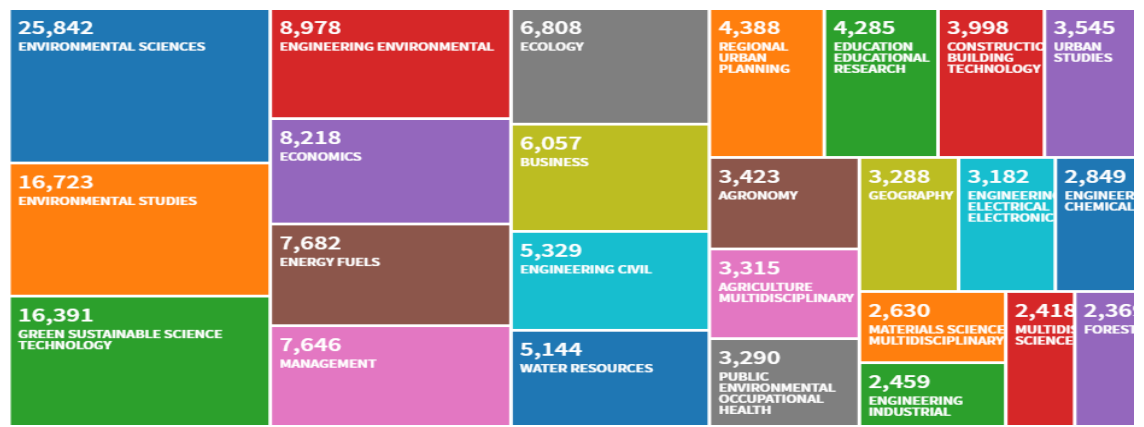

Fig. no. 4: Sustainability in Web of Science Categories

Source: Processing results from http:/ / wcs.webofknowledge.com/ $\mathrm{R} A$ / analyze.do

\section{Research Questions / Aim of the Research}

If e-governance involves, in particular, the inclusion of information and communication technologies in the life of organizations then there will certainly be mutations in the management and development of human resources(Rădulescu, 
Bodislav, \& Burlacu, 2018)(Burlacu, 2012), both of those directly involved in the management of electronic solutions (Burlacu, Enache, \& Stefan, 2013)and of staff who indirectly experience the impact of these technologies in their daily work (Burlacu \& Jiroveanu, 2011).

\section{Methodology of Research}

The main research method used was documentary analysis. This has been accomplished thanks to the access to international databases through ANELIS PLIS 2020 (National Electronic Access to Scientific and Research), a project co-financed by the European Regional Development Fund through the Competitiveness Operational Program 2014-2020. Our university is a beneficiary and has access to a list of electronic resources such as: Science Direct, Springer Nature, ProQuest, IEEE, APS, SAGE, AIP, Clarivate Anaytics, Scopus etc.

Due to the many bibliographic references found in these databases, we chose VOS viewer as a tool for analyzing visual representations to highlight the correlations between concepts.

VOSviewer is described by creators as a software tool for building and viewing bibliometric networks. It is also mentioned that bibliometric networks may include both individual journals or publications, as well as researchers. Networks can be built based on quoting, bibliographic engagement, co-quoting, or co-author relationships. In choosing the software solution, I took into account whether it offers text mining functionality that could be used to build and visualize co-emergence networks of important terms extracted from a body of scientific literature.

\section{Findings}

A visual representation of the main concepts that were related to the concept of "human resources" is found in Fig. no. 5.

\section{is vosviewer}

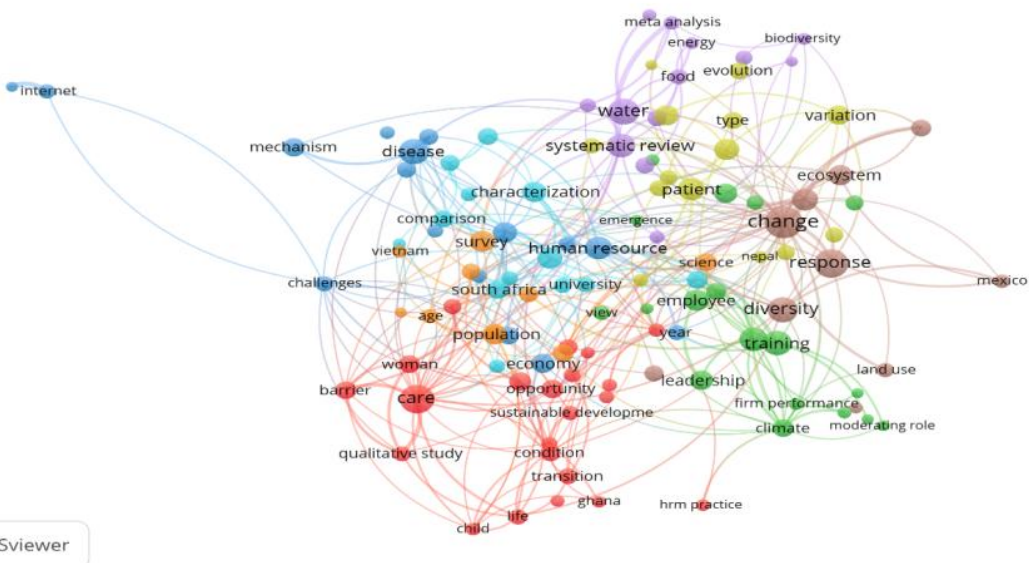

Fig. no. 5: Map of bibliographic references

Source: VOSviewer application with Web of Science data for 1975-2019 
From this representation we find that the relationship of human resources in relation to information and communication technologies has found a special place which determines us to investigate this link more closely. This research gap identified in the existing literature suggests possible future directions for our further research.

\section{Literature Review}

Recent studies show that an exponential growth in human economic expansion (Rădulescu et al., 2018)has had a direct effect on the environment as well as on the natural resources of the world, and engaging in social action to redress the situation is very limited (Chams \& García-Blandón, 2019), so an analysis of the impact of new technologies on human resources is required (Rădulescu et al., 2018). Some research has explored how sustainable human resource management practices influence the relationship between innovation output and customer satisfaction (Wikhamn, 2019). Other research has investigated the link between green management of human resources management and ecological supply chain management (ie external and internal practices) as well as influence on the triple bottom line of sustainable performance (ie, environment, social and economic performance)(Zaid, Jaaron, \& Talib Bon, 2018). Some studies have analyzed the sustainable management of human resources from a temporary perspective. According to them, the first definitions of a sustainable human resource management have focused on sustainable work systems, given the economic, social and environmental dimensions. The same studies show that there has been a second wave of studies that included studies related to systematics, sustainability and human resource management, including foreign research on human resources strategies and the impact of staff reductions, and recently as a last wave of studies interdisciplinary approach that underlines a wider understanding of the role of HRM in the social debate on sustainability(Macke \& Genari, 2019).

\section{Discussions}

Beyond the references found in the literature, the question that generated this research remains open, namely: How does e-governance affect human resource development?

Two new research directions have emerged from our analyzes: one concerns the cost of integrating new technologies into the organization and resistance to change, and the other concerns labor productivity. Without trying to give a comprehensive answer to our question, we have identified rather two suspicions that we will follow in our forthcoming research:

1. The cost of staff training for new instruments and their resistance to change (fear of the unknown)

Much of the literature focusing on organizational change suggests that change often fails because of employees' resistance due to their personal fears that change will affect them in any way. Employees are often afraid of changes that could lead to changes in comfortable social dynamics and to additional, less desirable or even more difficult tasks. (Wright, Christensen, \& Isett, 2013)

2. Reducing staff productivity due to new tools 
Employees selectively maintain the effective elements of performance routines and integrate them with newer and more efficient ones. Consequently, these employees often face difficulties and tensions in terms of maintaining previous performance levels, while adapting to the new job requirements. (CARTER, ARMENAKIS, FEILD, \& MOSSHOLDER, 2013)

\section{Conclusion}

Human resources have represented and are still the most important resource in an organization as well as in a society or country. Demographic issues should be debated in particular from one country to another, as there are major differences in both the size of human resources and the renewal of this resource from birth, migration, retirement age, adaptability and flexibility of the place work, etc. But the common denominator that the countries of today have in the globalization era can represent the astounding proliferation of computer technology and communication technology in almost all areas. The gap in the literature allows our future research to focus on innovative aspects of the role of e-governance in human resource development.

\section{References}

BURLACU, S. (2012). E-Faculty-Management Software Solution For Public Administration And Management Faculty. In Proceedings of Administration and Public Management International Conference (Vol. 2012, pp. 74-83). Research Centre in Public Administration and Public Services, Bucharest, Romania.

Burlacu, S., Enache, A. C., \& Stefan, C. (2013). INcreator - INNOVATIVE Software Tool for Creation of Adaptive Educational Digital Conten'T. In Roceanu, I and Stanescu, I and Barbieru, D (Ed.), QUALITY AND EFFICIENCY IN E-LEARNING, VOL 2 (pp. 238-242). PANDURI ST, 6872, BUCHAREST, 00000, ROMANIA: CAROL I NATL DEFENCE UNIV PUBLISHING HOUSE.

Burlacu, S., \& Jiroveanu, D. C. (2011). THE DEVELOPE OF SOFTWARE SOLUTION FOR SUPPLY CHAIN MANAGEMENT. REVISTA DE MANAGEMENT COMPARAT INTERNATIONAL/REVIEW OF INTERNATIONAL COMPARATIVE MANAGEMENT, 12(6), 140-145.

Chams, N., \& García-Blandón, J. (2019). On the importance of sustainable human resource management for the adoption of sustainable development goals. Resources, Conservation and Recycling, 141(September 2018), 109-122. https://doi.org/10.1016/j.resconrec.2018.10.006

Macke, J., \& Genari, D. (2019). Systematic literature review on sustainable human resource management. Journal of Cleaner Production, 208, 806-815. https://doi.org/10.1016/j.jclepro.2018.10.091

Rădulescu, C. V, Bodislav, D. A., \& Burlacu, S. (2018). DEMOGRAPHIC EXPLOSION AND IT GOVERNANCE IN PUBLIC INSTITUTIONS. Managerial Challenges of the Contemporary Society. Proceedings, 11(1), 18.

Wikhamn, W. (2019). Innovation, sustainable HRM and customer satisfaction. International Journal of Hospitality Management, 76(May 2018), 102-110. https://doi.org/10.1016/j.ijhm.2018.04.009

Zaid, A. A., Jaaron, A. A. M., \& Talib Bon, A. (2018). The impact of green human resource management and green supply chain management practices on sustainable performance: An empirical study. Journal of Cleaner Production, 204, 965-979. https://doi.org/10.1016/j.jclepro.2018.09.062 